\title{
Efeito da distribuição granulométrica na secagem de concretos refratários
}

\section{(Effect of particle size distribution on the drying behavior of refractory castables)}

\author{
M. D. M. Innocentini', J. Yamamoto ${ }^{1}$, C. Ribeiro' ${ }^{1}$ R. G. Pileggi ${ }^{1}$, A. C. Rizzi Jr. ${ }^{1}$, \\ L. R. M. Bittencourt ${ }^{2}$, R. P. Rettore ${ }^{2}$, V. C. Pandolfelli ${ }^{1}$ \\ ${ }^{1}$ Universidade Federal de S. Carlos, DEMa \\ Rod. Washington Luiz, km 235, C.P. 676, 13565-905, S. Carlos, SP \\ pmmi@iris.ufscar.br,vicpando@power.ufscar.br \\ ${ }^{2}$ Magnesita S.A., Cidade Industrial, Contagem, MG, 32210-050.
}

\begin{abstract}
Resumo
Este trabalho teve como objetivo investigar o efeito da distribuição granulométrica sobre parâmetros de permeabilidade, porosidade aparente e secagem de concretos refratários de alta alumina. Verificou-se a influência de ambas as distribuições discreta e acumulada, baseadas no modelo de empacotamento de Andreasen. Ensaios de permeabilidade ao ar à temperatura ambiente permitiram correlacionar os tipos de poros presentes no concreto com a facilidade de escoamento de fluidos. Ensaios de permeabilidade em temperaturas elevadas foram utilizados para acompanhar a decomposição de hidratos. A análise termogravimétrica permitiu associar as características da estrutura com a facilidade de eliminação de água durante o processo de secagem. Os resultados mostraram que o aumento no teor de agregados favorece a permeabilidade e a secagem do concreto. A composição formulada com matriz grossa e agregados finos foi a que apresentou melhor desempenho global de secagem.
\end{abstract}

Palavras-chave: secagem, distribuição granulométrica, permeabilidade, agregados, concretos refratários.

\section{INTRODUÇÃO}

A secagem é uma etapa crítica no processamento da maioria dos produtos cerâmicos, envolvendo desde isolantes e capacitores para a indústria eletrônica até tijolos e revestimentos refratários para fundições e siderúrgicas. A escolha de um programa de secagem agressivo pode levar à degradação na resistência mecânica do produto, enquanto uma programação lenta pode não ser economicamente viável [1-4].

Embora a degradação mecânica decorrente de uma secagem inadequada possa variar em extensão conforme as características do produto, ela é essencialmente devida a uma única causa: se a geração de vapor d'água no interior da estrutura ocorrer mais rápido do que sua liberação para a superfície, então a pressão desen-

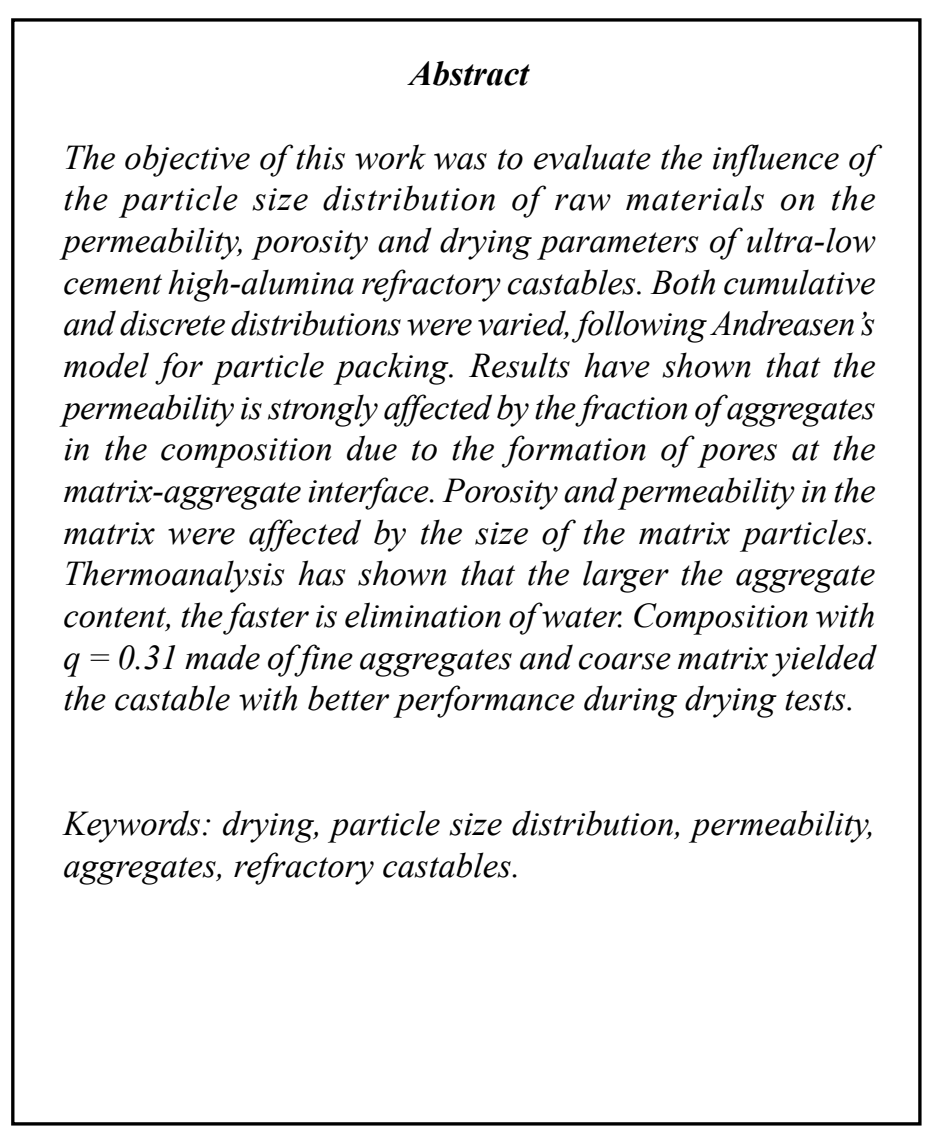

volvida no interior dos poros pode exceder a tensão de fratura do corpo, causando até mesmo sua explosão. A ocorrência deste fenômeno é particularmente crítica na área siderúrgica, seja pelo grande volume das peças envolvidas (o que pode levar a explosões catastróficas) ou pelo simples fato que o tempo de interrupção para reparos no revestimento refratário é extremamente oneroso para o processo.

O crescente avanço na tecnologia de concretos refratários tem levado à formulação de produtos considerados de alto desempenho, quer seja na forma de aplicação (bombeáveis, multifuncionais, etc), comportamento durante a secagem ou uso em alta temperatura. Em relação à secagem, a literatura tem mostrado que a otimização desse processo passa necessariamente pela melhoria nas características do corpo refratário, em especial de sua permeabilidade. Um 
corpo permeável evita o acúmulo de vapores em sua estrutura, fazendo com que o uso de rampas de aquecimento mais agressivas e curtas não levem à sua explosão.

Embora pouco explorada, uma das mais poderosas ferramentas disponíveis para a otimização das propriedades de um concreto é o ajuste granulométrico de suas matérias-primas constituintes. Estudos recentes têm mostrado que a distribuição de tamanho de partículas e o seu empacotamento durante o processamento determinam a quantidade e o formato dos poros da estrutura, influenciando a permeação de fluidos e conseqüentemente a eliminação de água durante o processo de secagem. Apesar disso, ainda são escassos na literatura os trabalhos que associam de forma clara e direta parâmetros de distribuição granulométrica do concreto com sua permeabilidade e facilidade de secagem.

Dentro deste contexto, o objetivo deste trabalho foi o de investigar a influência da distribuição granulométrica das matérias-primas na permeabilidade e na secagem de concretos refratários autoescoantes de alta alumina e ultra-baixo teor de cimento. Verificouse a influência de ambas as distribuições discreta e acumulada, baseadas no modelo de empacotamento de Andreasen. Os ensaios incluíram medidas de permeabilidade ao ar em baixa e alta temperatura (até $700^{\circ} \mathrm{C}$ ), porosidade aparente e análise termogravimétrica.

\section{PROCEDIMENTO EXPERIMENTAL}

Concretos refratários de alta alumina e ultrabaixo teor de cimento foram formulados de acordo com o modelo de empacotamento de Andreasen. As variáveis foram o coeficiente de distribuição (q) da curva granulométrica $(0,21,0,26$ e 0,31$)$ e a distribuição discreta de partículas das matérias-primas: MGAG, MGAF, MFAG e MFAF, onde as iniciais significam: $\mathrm{M}=$ Matriz, $\mathrm{A}=$ Agregado, $\mathrm{G}=$ Grosso, e F= Fino. $\mathrm{O}$ primeiro parâmetro representa a quantidade relativa entre matriz e agregado, enquanto o segundo quantifica a relação de tamanhos das partículas das frações de agregados e matriz, para uma mesma distribuição acumulada. As Figs. 1 e 2 apresentam as curvas de distribuição de partículas para as formulações analisadas neste trabalho.

Em todas as formulações, os teores de água (15\% volume) e de cimento de aluminato de cálcio ( $2 \%$ peso) foram mantidos constantes. Todas as matérias-primas (AEB 4/10 AEB 200F, A1000SG,

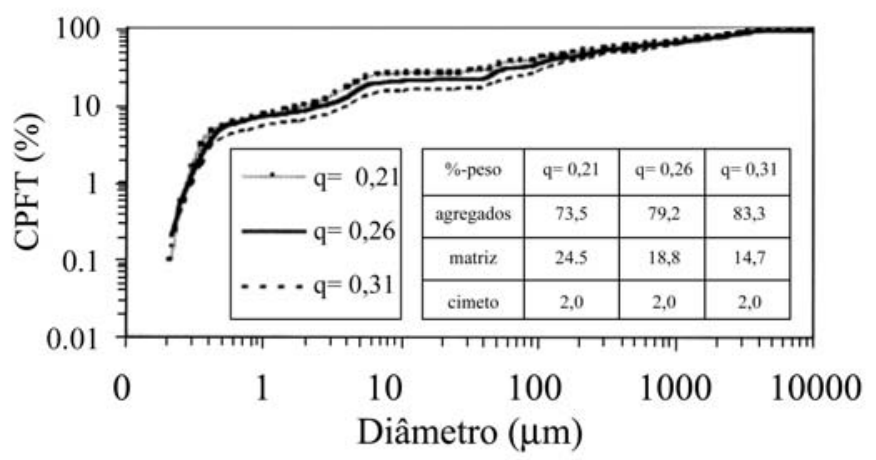

Figura 1: Curvas de distribuição acumulada de partículas conforme o modelo de Andreasen para os concretos formulados neste trabalho. [Figure 1: Cumulative particle size distribution of compositions formulated in this work according to Andreasen model.]
A3000FL, CA270) foram fornecidas pela Alcoa Brasil e E.U.A. Os corpos-de-prova foram moldados como cilindros de 7,5 cm de diâmetro e 2,5 cm de espessura e curados por 24 horas em temperatura ambiente $\left(25^{\circ} \mathrm{C}\right)$ e mantidos por outras 24 horas a $110^{\circ} \mathrm{C}$ para remoção de toda a umidade residual.

As medidas de porosidade aparente foram realizadas pelo método de Arquimedes conforme a norma ASTM C20-92.

Os ensaios de permeabilidade ao ar em temperatura ambiente foram realizados em equipamento descrito em [5]. Os dados experimentais foram ajustados segundo a equação de Forchheimer para fluidos compressíveis [6-11].

$$
\frac{\mathrm{P}_{\mathrm{e}}^{2}-\mathrm{P}_{\mathrm{s}}^{2}}{2 \mathrm{P}_{\mathrm{s}} \mathrm{L}}=\frac{\mu \mathrm{v}_{\mathrm{s}}}{\mathrm{K}_{1}}+\frac{\rho \mathrm{v}_{\mathrm{s}}^{2}}{\mathrm{~K}_{2}}
$$

na qual $\mathrm{P}_{\mathrm{e}}$ e $\mathrm{P}_{\mathrm{s}}$ são respectivamente as pressões absolutas do ar na entrada e na saída da amostra, $\rho$ e $\mu$ são respectivamente a densidade e a viscosidade do ar, $\mathrm{v}_{\mathrm{s}}$ é a velocidade superficial do ar, calculada pela divisão da vazão volumétrica $(\mathrm{Q})$ pela área frontal e livre para escoamento (A). Os parâmetros $\mathrm{k}_{1}$ e $\mathrm{k}_{2}$ são constantes conhecidas respectivamente como permeabilidades Darciana e nãoDarciana.

As constantes de permeabilidade, propriedades dependentes apenas do meio poroso, foram obtidas neste trabalho por ajuste dos dados experimentais de $\mathrm{v}_{\mathrm{s}}$ versus $\left[\mathrm{P}_{\mathrm{e}}^{2}-\mathrm{P}_{\mathrm{s}}^{2}\right] / 2 \mathrm{P}_{\mathrm{s}} \mathrm{L}$ na equação $(\mathrm{A})$ através do método dos mínimos quadrados. Em cada ensaio, os valores de pressão e vazão foram coletados em tréplica para garantir a confiabilidade da curva. Considerou-se $\mu_{\mathrm{ar}}=1,8 \times 10^{-5} \mathrm{~Pa} . \mathrm{s}$ e $\rho_{\mathrm{ar}}=1,08 \mathrm{~kg} / \mathrm{m}^{3}$ para $\mathrm{T}_{\mathrm{amb}}=25^{\circ} \mathrm{C}$ e $\mathrm{P}_{\mathrm{atm}}=\mathrm{P}_{\mathrm{s}}=690 \mathrm{mmHg}$.

Os ensaios de permeabilidade em alta temperatura foram realizados em permeâmetro $[7,8]$. A técnica consistiu na passagem de ar, sob pressão constante, através de amostra com mesmas dimensões àquelas usadas nos testes de permeametria à temperatura ambiente. O monitoramento simultâneo da temperatura de entrada, de saída e da vazão de ar na saída da amostra permitiu a verificação de transformações mássicas, térmicas e fluidodinâmicas durante o processo de desidratação do concreto. Os ensaios foram realizados com taxa de aquecimento de $5^{\circ} \mathrm{C} / \mathrm{min}$ na faixa de 25 a $700{ }^{\circ} \mathrm{C}$.

$\mathrm{A}$ análise gravimétrica durante a secagem foi feita em ensaio à temperatura constante $\left(110^{\circ} \mathrm{C}\right)$ em equipamento desenvolvido em laboratório, monitorando-se a temperatura e a massa da amostra (em torno de $250 \mathrm{~g}$ ) em função do tempo. Neste ensaio não foi investigada a saída de hidratos, mas apenas a facilidade de saída de água livre. Para isso, os corpos, previamente secos a $110^{\circ} \mathrm{C}$ foram saturados em água para preenchimento de todos os poros. $\mathrm{O}$ parâmetro de análise foi a umidade residual do corpo, definida como:

$$
\text { Umidade residual }(\%)=100 \frac{\mathrm{M}-\mathrm{M}_{\mathrm{S}}}{\mathrm{M}_{\mathrm{i}}-\mathrm{M}_{\mathrm{S}}}
$$

onde: $\mathrm{M}=$ massa total do corpo no instante $\mathrm{t}, \mathrm{M}_{\mathrm{s}}=$ massa final do corpo após a secagem, $\mathrm{M}_{\mathrm{i}}=$ massa inicial do corpo antes da secagem.

\section{RESULTADOS E DISCUSSÃO}

A Fig. 3 apresenta os resultados obtidos por permeametria em temperatura ambiente. Observa-se claramente que, fixando-se a 

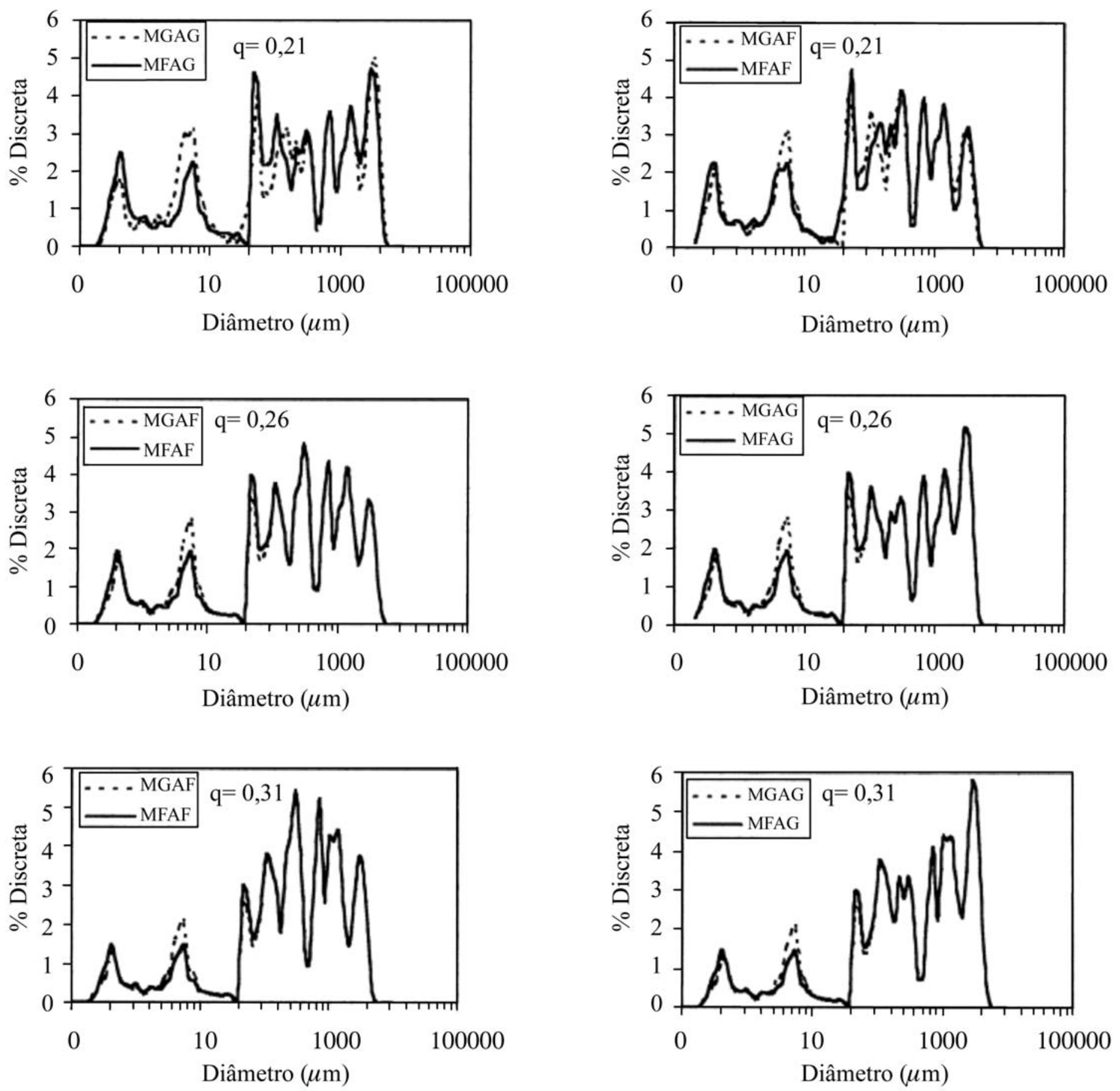

Figura 2: Distribuições discretas utilizadas na formulação dos concretos refratários analisados neste trabalho. [Figure 2: Discrete particle size distributions of compositions formulated in this work.]

distribuição discreta, o aumento no coeficiente de Andreasen (q) causou um aumento em ambas constantes de permeabilidade, sendo mais significativo para a constante não-Darciana $\mathrm{k}_{2}$, que chegou a aumentar 3 ordens de grandeza entre q=0,21 e 0,31. Em relação a esse efeito, foi demonstrado recentemente [6] que existem basicamente duas classes de poros na estrutura de um concreto refratário que afetam a sua permeabilidade. A primeira classe refere-se aos poros existentes na matriz, gerados por falhas no empacotamento das partículas. Essa fração é fortemente afetada pela quantidade de água e de cimento adicionados ao concreto durante o processamento, podendo causar aumento proporcional na porosidade e permeabilidade do material.

Uma segunda classe importante de poros decorre do empacotamento falho das partículas da matriz na superfície dos agregados. Pela ocorrência de efeitos de parede, as partículas da matriz empacotam-se com menor eficiência na interface com os agregados, formando uma região com gradiente de porosidade cujo valor reduz-se a partir da interface. A espessura da zona afetada pelos efeitos de parede pode ser equivalente ao tamanho das maiores partículas da matriz [12]. Os poros interfaciais são maiores em extensão do que poros presentes na matriz e representam um caminho mais fácil e menos tortuoso para a percolação de fluidos, tendo 


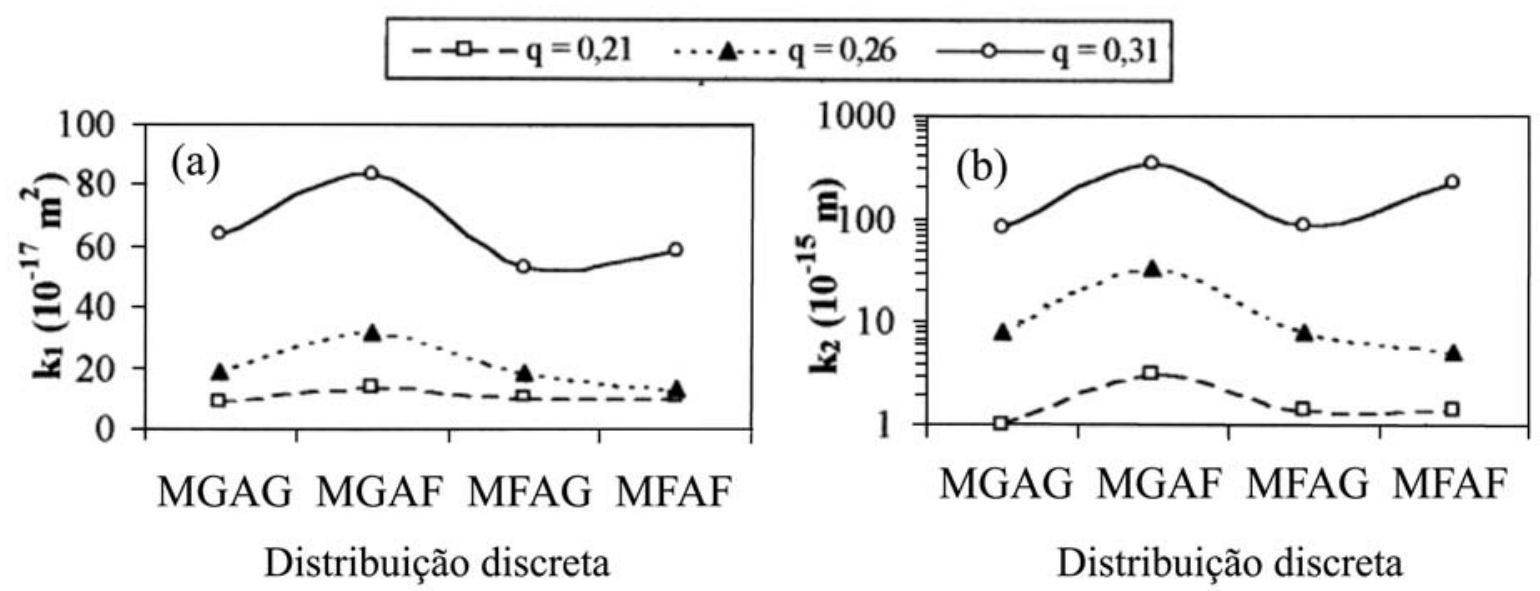

Figura 3: Variações observadas na permeabilidade de um concreto refratário em decorrência de alterações na distribuição acumulada e na distribuição discreta de partículas de suas matérias-primas. (a) constante de permeabilidade Darciana, $\mathrm{k}_{1}$; (b) constante de permeabilidade não Darciana, $\mathrm{k}_{2}$. [Figure 3: Changes observed in permeability due to different discrete and cumulative particle size distributions. (a) Darcian permeability constant, $k_{1}$. (b) Non-Darcian permeability constant, $\left.k_{2}.\right]$
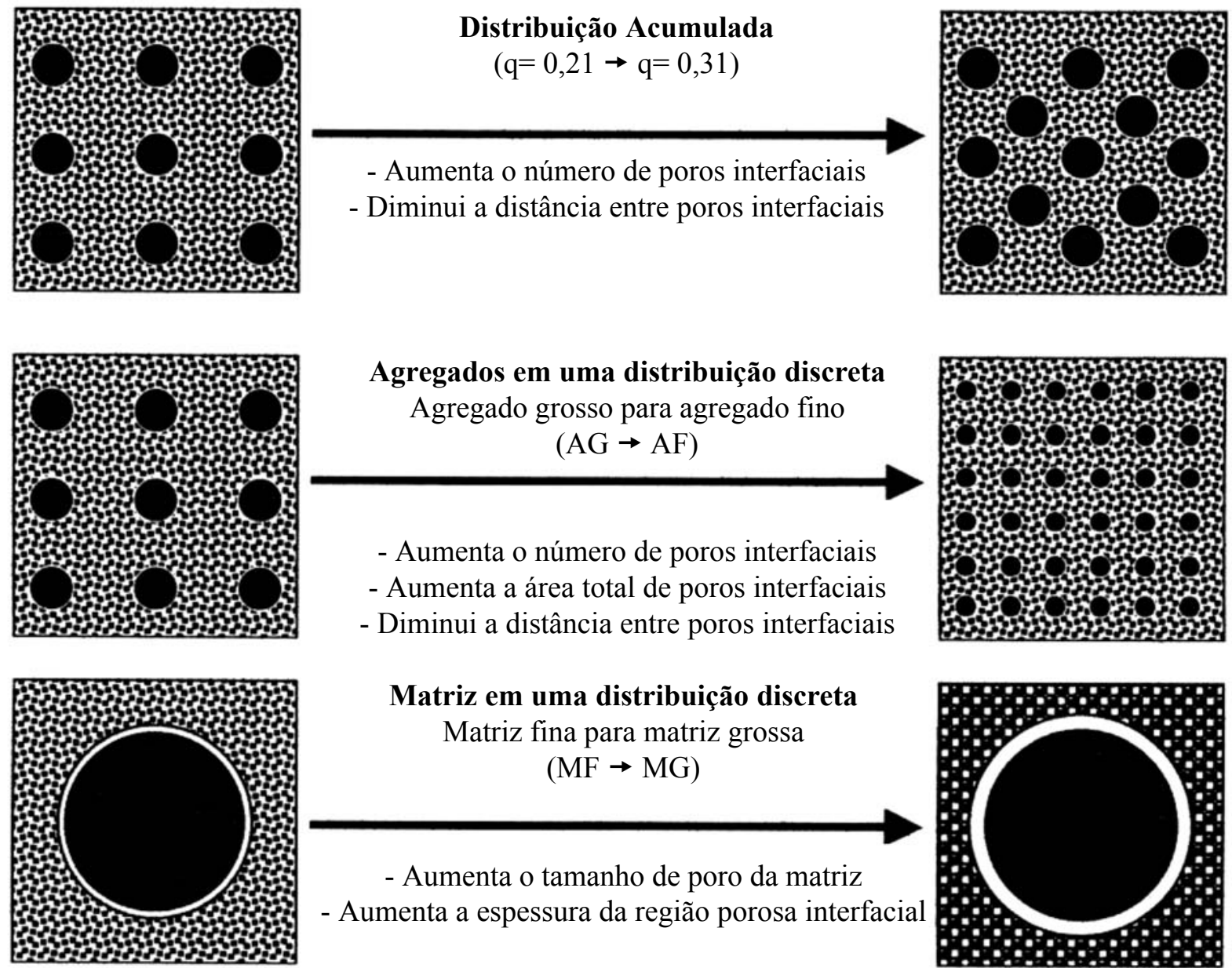

Matriz em uma distribuição discreta

Matriz fina para matriz grossa

$(\mathrm{MF} \rightarrow \mathrm{MG})$

\section{LEGENDA}

弱Matriz $\square$ Agragado $\square$ Poro

- Aumenta o tamanho de poro da matriz - Aumenta a espessura da região porosa interfacial

Figura 4: Parâmetros da distribuição granulométrica de partículas que causam aumento de permeabilidade em um concreto refratário. [Figure 4: Factors in the particle size distribution that cause permeability changes in a refractory castable.] 
grande impacto sobre a permeabilidade do concreto.

Assim, o aumento no coeficiente de Andreasen (q) representa na verdade um aumento na proporção entre agregados e matriz, e indiretamente na quantidade de interfaces disponíveis para o escoamento do ar. A Fig. 3 mostra que um aumento no parâmetro q de 0,21 para 0,31 , causado pela adição de $10 \%$ no teor de agregados (de $73,5 \%$ para $83,3 \%$ ) resultou em um aumento médio de 6 vezes na constante $\mathrm{k}_{1}$ e de 107 vezes em $\mathrm{k}_{2}$.

Em relação à influência da distribuição discreta, a Fig. 3 mostra uma permeabilidade superior $\left(50 \%\right.$ em média para $\mathrm{k}_{1}$ e $226 \%$ em média para $\mathrm{k}_{2}$ ) para a composição com matriz grossa e agregados finos (MGAF). Esse aumento ficou mais evidente à medida que o teor de agregados (q) aumentou na composição. Assim, o concreto MGAF com $\mathrm{q}=0,31$ apresentou o maior nível de permeabilidade $\left(\mathrm{k}_{1}=83,42 \times 10^{-17} \mathrm{~m}^{2}\right.$ e $\left.\mathrm{k}_{2}=349,19 \times 10^{-15} \mathrm{~m}\right)$ dentre todas as composições estudadas.

A explicação para esse comportamento é mais complexa e está relacionada à alteração provocada pela distribuição discreta de partículas sobre a quantidade e o tamanho dos poros na matriz e na interface matriz-agregado.

A alteração na distribuição discreta de partículas finas resulta em alteração no empacotamento da matriz. Assim, espera-se que em uma matriz fina (MF) os poros sejam em maior número, porém menores e mais tortuosos do que em uma matriz grossa (MG), dificultando o escoamento de fluidos. Por outro lado, o efeito da distribuição discreta de agregados está relacionado ao tamanho e número dos poros interfaciais. Um concreto com agregados finos (AF) possui um número maior de poros circunferenciais, embora de menor comprimento, do que um concreto com agregados grossos (AG). Embora o volume total desses poros seja menor que os poros contidos na matriz, sua contribuição para a permeabilidade é muito mais sensível [6].

Adicionalmente, a relação entre os tamanhos das partículas de matriz

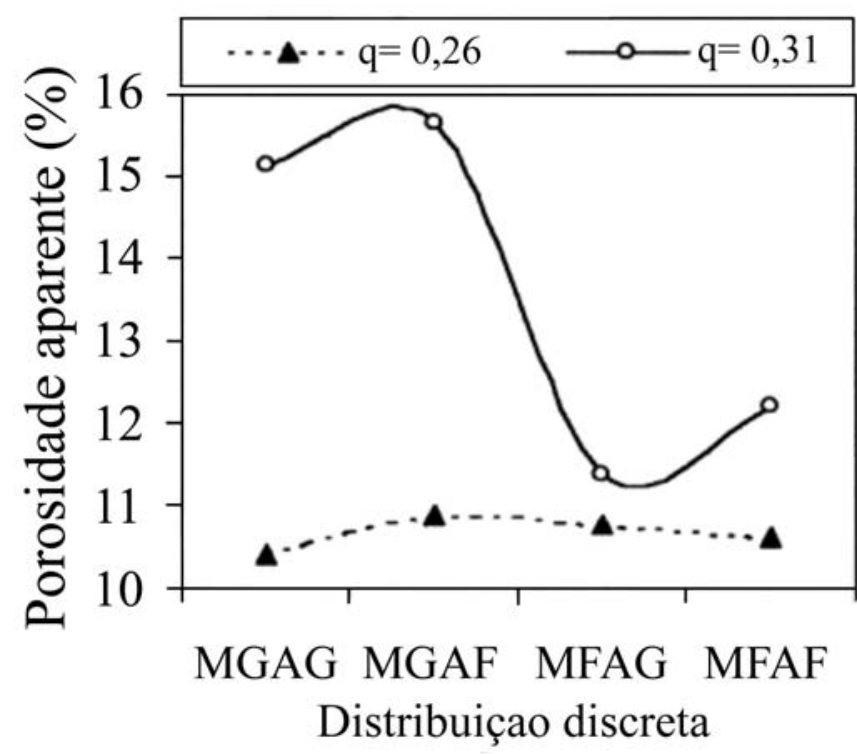

Figura 5: Variações observadas na porosidade aparente de um concreto refratário em decorrência de alterações na distribuição acumulada e na distribuição discreta de partículas de suas matérias-primas.

[Figure 5: Changes observed in the apparent porosity of refractory castables due to variations in the cumulative and discrete particle size distribution.] e agregado também pode interferir no empacotamento da região interfacial, através do efeito parede [6,12]. Assim, uma matriz grossa empacota-se de modo menos eficiente do que uma matriz fina sobre a superfície dos agregados, gerando uma região porosa interfacial de maior diâmetro, embora de extensão idêntica em ambos os casos. A Fig. 4 exemplifica os mecanismos de aumento na permeabilidade de um concreto refratário através de alterações nas distribuições acumulada e discreta de partículas.

A Fig. 5 mostra que a porosidade aparente das amostras é também significantemente afetada pela distribuição granulométrica. Embora o aumento no teor de agregados de $\mathrm{q}=0,21$ para 0,31 tenha causado aumento em ambos os parâmetros, a maior variação ficou evidenciada para os corpos com matriz grossa, que tiveram porosidade média de $15 \%$ contra $12 \%$ para os corpos com matriz fina. Esse resultado confirma que o empacotamento da matriz é o principal fator de aumento da porosidade aparente de um concreto.

A Fig. 6-a confirma que o aumento no teor de agregados resultou efetivamente em uma maior facilidade de secagem para o concreto, sendo que a composição com $\mathrm{q}=0,31$ apresentou a maior velocidade de secagem. A Fig. 6-b mostra, no entanto, que para um mesmo teor de agregados, corpos com matriz grossa (MG) são ligeiramente mais efetivos para a eliminação de água do que corpos com matriz fina. No outro extremo, o corpo com matriz fina e agregados grossos (MFAG)
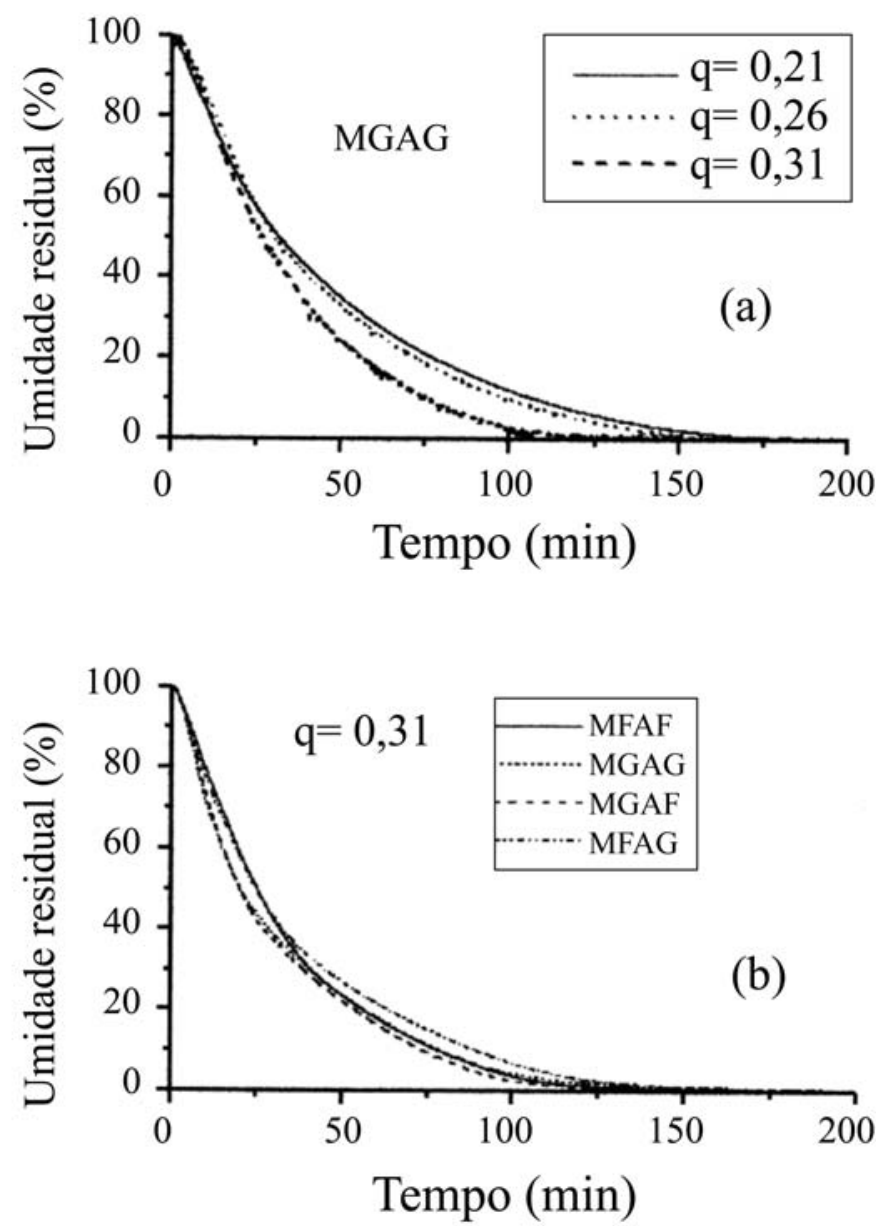

Figura 6: Variações observadas na secagem em temperatura constante $\left(110^{\circ} \mathrm{C}\right)$ de um concreto refratário em decorrência de alterações na (a) distribuição acumulada e (b) distribuição discreta de partículas de suas matérias-primas. [Figure 6: Changes observed in the drying behavior of refractory castables due to variations in the (a)cumulative and (b) discrete particle size distribution.] 


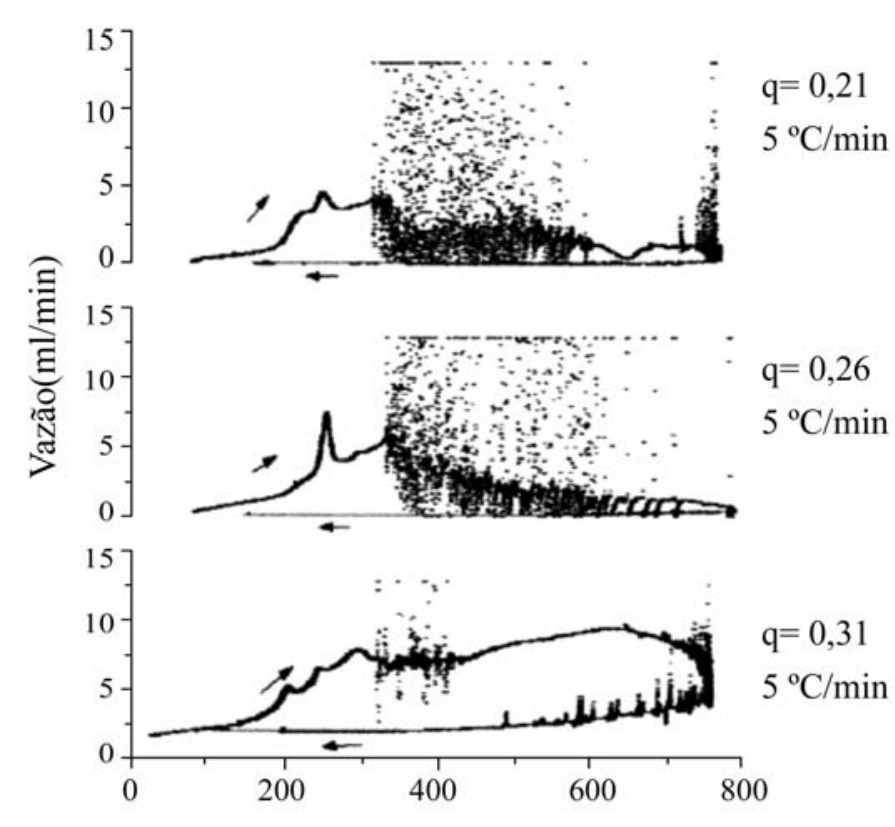

Figura 7: Variações observadas no perfil de permeabilidade e de saída de hidratos em altas temperaturas decorrentes de alterações na distribuição acumulada de partículas das matérias-primas de um concreto refratário. As amostras foram previamente secas a $110^{\circ} \mathrm{C}$ por $24 \mathrm{~h}$ para eliminação de umidade residual.

[Figure 7: Changes observed in the dehydration behavior of refractory castables due to variations in the cumulative particle size distribution. Samples were previously dried at $110^{\circ} \mathrm{C}$ for 24 hours to eliminate residual moisture.]

foi o que apresentou menor velocidade de secagem, refletindo uma menor porosidade da matriz e um número menor de poros na interface matriz-agregado.

A Fig. 7 mostra o perfil de permeabilidade durante o tratamento térmico das amostras com diferentes distribuições acumuladas. Tais amostras foram previamente secas a $110^{\circ} \mathrm{C}$ por 24 horas para eliminação de toda a umidade residual, de modo que fosse observada apenas a decomposição de hidratos durante o ensaio de permeabilidade em alta temperatura. Assim, os picos de vazão observados entre 180 e 250 ${ }^{\circ} \mathrm{C}$ refletem a decomposição de $\mathrm{C}_{3} \mathrm{AH}_{6}\left(3 \mathrm{CaO} \cdot \mathrm{Al}_{2} \mathrm{O}_{3} \cdot 6 \mathrm{H}_{2} \mathrm{O}\right)$, que é um dos principais hidratos gerados nas condições de cura utilizadas neste trabalho. A grande nuvem de pontos observada para as amostras com $\mathrm{q}=0,21$ e $\mathrm{q}=0,26$, entre as temperaturas de $300^{\circ}$ e $600^{\circ} \mathrm{C}$, reflete, por sua vez, a decomposição relativamente caótica da gibsita $\left(\mathrm{AlO}(\mathrm{OH})_{3}\right), \mathrm{C}_{3} \mathrm{AH}_{1,5}\left(3 \mathrm{CaO} \cdot \mathrm{Al}_{2} \mathrm{O}_{3} \cdot 1,5 \mathrm{H}_{2} \mathrm{O}\right)$ e boemita $(\mathrm{Al}(\mathrm{OH}))$. A diferença marcante entre as curvas foi o menor nível de turbulência na saída dos hidratos, observado para a amostra com $\mathrm{q}=0,31$, indicando provavelmente uma maior facilidade de escoamento do vapor d'água para fora da amostra. Esses resultados novamente parecem confirmar as tendências observadas nas Figs. 3 e 6 de que o aumento no teor de agregados favorece a permeação de fluidos e conseqüentemente a eliminação de água durante o processo de secagem.

Embora tais tendências necessitem confirmação, o seguinte quadro pode ser montado a partir da análise global dos resultados deste trabalho: embora os poros interfaciais representem o caminho mais curto para a saída de água do corpo cerâmico, é a permeabilidade da matriz que é o fator limitante para a secagem. Isso ocorre porque são os poros da matriz (em maior volume) que retêm praticamente toda á água usada no processamento. Assim, quanto mais porosa for a matriz, mais fácil será o deslocamento da água para os poros da interface e conseqüentemente para fora do corpo cerâmico. Na verdade, a atuação conjunta de uma matriz porosa e permeável (seja pela adição de água na mistura ou pelo uso de uma matriz grossa) com uma rede de poros interfaciais permeáveis e pouco tortuosos (pelo aumento no teor ou pela diminuição no diâmetro dos agregados) parece ser a melhor combinação para a obtenção de uma secagem rápida e eficaz.

\section{CONCLUSÕES}

Este trabalho teve como objetivo verificar como alterações nas distribuições discreta e acumulada de partículas das matérias-primas afetam a permeabilidade e a secagem de concretos refratários de alta alumina. Os resultados indicam que existem dois mecanismos que controlam a permeação de fluidos no concreto. Os poros na matriz, responsáveis pela retenção de água no concreto, têm porosidade e permeabilidade controlada pela distribuição discreta de partículas da matriz. Por outro lado, os poros originados na interface matriz-agregado são responsáveis pela geração de atalhos para a eliminação de água para fora da estrutura. A quantidade e o tamanho desses poros estão relacionados à distribuição acumulada (teor de agregados) e pela distribuição discreta (tamanho dos agregados). Em geral, corpos com agregados finos foram os mais permeáveis, enquanto corpos com matriz grossa foram os que apresentaram melhor desempenho durante a secagem.

\section{AGRADECIMENTOS}

Os autores agradecem a FAPESP e Alcoa Alumínio S.A. pelo apoio na realização deste trabalho.

\section{REFERÊNCIAS}

[1] W. E. Lee, R. E. Moore, "Evolution of in-situ refractories in the 20th century", J. Am. Ceram. Soc. 81, 6 (1998) 1385-1410.

[2] R. E. Moore, J. D. Smith, W. L. Headrick, Jr, T. P. Sander, "Monolithic dewatering theory testing and practice: new challenges", In: 32nd Annual Symposium on Refractories, The Am. Ceram. Soc., St. Louis Section, (1996) 26.

[3] W. H. Gitzen, L. D. Hart, "Explosive spalling of refractory castables bonded with calcium aluminate cement", Am. Ceram. Soc. Bull. 40, 8 (1961) 503-507, 510.

[4] S. Arnosti Jr., M. D. M. Innocentini, V. C. Pandolfelli, "Variáveis críticas no processo de secagem de concretos refratários", Cerâmica 45, 292/293 (1999)107-118.

[5] M. D. M. Innocentini, A. R. F. Pardo, V. C. Pandolfelli, "Permeability of high-alumina self-flow refractory castables", In: Proceedings of the Unified International Technical Conference on Refractories - UNITECR' 99, Berlin - Germany, (1999) 93-96.

[6] M. D. M. Innocentini, A. R. Studart, R. G. Pileggi, V. C. Pandolfelli, "PSD effect on the permeability of refractory castables", aceito para publicação no Am. Ceram. Soc. Bull. (2001).

[7] M. D. M. Innocentini, M. G. Silva, B. A. Menegazzo, V. C. Pandolfelli, "Permeability of refractory castables at hightemperatures", J. Am. Ceram. Soc. 84, 3 (2001) 645-647.

[8] C. Ribeiro, M. D. M. Innocentini, V. C. Pandolfelli, "Dynamic permeability behavior during drying of refractory castables based on calcium-free alumina binders", J. Am. Ceram. Soc.

84,

1 (2001) 248-250.

[9] M. D. M. Innocentini, V. C. Pandolfelli, "Considerações sobre 
estimativa da permeabilidade em concretos refratários através das equações de Darcy e de Forchheimer", Cerâmica 45, 292/293 (1999) 61-67.

[10] M. D. M. Innocentini, A. R. F. Pardo, V. R. Salvini, V. C. Pandolfelli, "How accurate is Darcy's law for refractories", Am. Ceram. Soc. Bull. 78, 11 (1999) 64-68.
[11] M. D. M. Innocentini, V. C. Pandolfelli, "Permeable porosity of refractory castables evaluated by water-expulsion porosimetry technique”, J. Am. Ceram. Soc. 84, 1 (2001) 236-238.

[12] K. L. Scrivener, K. M. Nemati, "The percolation of pore space in the cement paste/aggregate interfacial zone of concrete", Cement and Concrete. Research 26, 1 (1996) 35-40.

Rec. 30/03/01, Ac. 17/08/01) 